\title{
MEMÓRIAS SENTIMENTAIS DE JOÃO MIRAMAR: \\ CAMINHOS DA RECEPÇÃO CRÍTICA.
}

Juarez Poletto

Escritor. Mestre em Literatura Brasileira (UFPR). Professor da PUC-PR e da unidade de Curitiba do CEFET-PR.

\section{BANDEIRAS}

A implicação estética reside no fato de já a recepção primária de uma obra pelo leitor encerrar uma avaliação de um valor estético, pela comparação com outras obras já lidas. A implicação histórica manifesta-se na possibilidade de, numa cadeia de recepções, a compreensão dos primeiros leitores ter continuidade e enriquecer-se de geração em geração, decidindo, assim, o próprio significado histórico de uma obra e tornando visível sua qualidade estética.[i]

\section{Hans Robert Jauss}

O modernismo brasileiro, na sua fase heróica (1922-1930), fundamenta-se numa proposta de ruptura com o academicismo e com as proposições artísticas e temáticas precedentes. O rompimento começa a se configurar já na conferência de abertura da Semana de Arte Moderna - A emoção estética na arte moderna - proferida por Graça Aranha, quando questiona a associação da arte com o Belo: "Onde repousa o critério infalível do belo?"[ii]; ou já na noite seguinte, com Menotti del Picchia na conferência Arte Moderna:

Só isso? Não. Não nos limitamos somente a banir da gaiola das rimas o fetiche 'femina' nem a rechaçar para a montanha a tropa olímpica dos deuses. Queremos libertar a poesia do presídio canoro das fórmulas acadêmicas, dar elasticidade e amplitude aos processos técnicos, para que a idéia se transubstancie, sintética e livre, na carne fresca do Verbo, sem deitá-la, antes, no leito de Procusto dos tratados de versificação.[iii]

A essas duas citações que marcam o sentido estético da visão moderna (entendamos "estético" não na proposição de W. Iser, como o que nasce a partir do ato de recepção), some-se, da mesma conferência de del Picchia, uma visada ideológica: 
Não! Paremos diante da tragédia hodierna. A cidade tentacular radica seus gânglios numa área territorial que abriga 600.000 almas. Há na angústia e na glória da sua luta odisséias mais formidáveis que as que cantou o aedo cego: a do operário reivindicando seus direitos; a do burguês defendendo sua arca; a dosfuncionários deslizando nos trilhos dos regulamentos; a do industrial combatendo o combate da correspondência; a do aristocrata exibindo o seu fausto; a do político assegurando a sua escalada; a da mulher quebrando as algemas da escravidão secular nos gineceus eventrados pelas idéias libertárias postbellum... Tudo isso - e o automóvel, os fios elétricos, as usinas, os aeroplanos, a arte - tudo isso forma os nossos elementos da estética moderna.[iv]

O casamento entre o ideológico e o estético é proposta modernista que se confirma no Manifesto da Poesia Pau-Brasil, de Oswald de Andrade, quando já em sua primeira postulação afirma: "A poesia existe nos fatos. Os casebres de açafrão e de ocre nos verdes da favela, sob o azul cabralino, são fatos estéticos"[v]. Ao conferir à realidade mais chã a qualidade de estético (no sentido mais genérico de Belo), Oswald carrega de sentido ideológico a assertiva. O que também fez Graça Aranha na revista Estética, no Rio de Janeiro, em 1924, logo após o rompimento com a Academia Brasileira de Letras: "A ação do jovem moderno será eminentemente social. A estética que o inspira lhe patenteará pela análise o que é o Brasil e quais os trabalhos externos a que se deve consagrar"[vi]. Aí está a revelação de uma proposta que quer carregar uma bandeira nova, não laudatória mas analítica do Brasil. "Ver com olhos livres"[vii] escreve Oswald de Andrade, livres para essa nova forma de construir e de pensar as artes no Brasil em função de uma nova proposta de sociedade.

Nesse novo quadro moderno se insere Memórias Sentimentais de João Miramar de Oswald de Andrade, que vem a público em 1924 e causa polêmica por suas proposições inovadoras associadas à figura controvertida do autor.

Este trabalho se propõe, através da leitura da crítica que se constituiu em torno da obra, a levantar a história da recepção de Memórias Sentimentais de João Miramar, e dará ênfase aos aspectos estéticos e ideológicos dessas leituras. Para tanto, levará em conta algumas análises secundárias, mas em especial as críticas de Antônio Cândido, Haroldo de Campos, Alfredo Bosi, Kenneth D. Jackson e Lúcia Helena. A escolha desses autores se deve ao fato de terem produzido os textos fundamentais da fortuna crítica em torno da obra em questão. Não há intenção de observar o viés da leitura do grande público, pois tanto quanto se sabe, a obra em análise não foi de apelo popular, sua repercussão atingiu a academia e, quando nela provocou objeção, as mais das vezes, esses protestos não foram além de comentários em jornais ou revistas. Parece não haver uma crítica consistente, que se oponha a Memórias Sentimentais de João Miramar. 
163 fragmentos concretizam a ficção irônica de Memórias Sentimentais de João Miramar, que inclui setenta e uma personagens, todos tipos, inclusive Miramar. Muitos dos nomes de personagens revelam humor e crítica social como Dr. Limão Bravo (crítico azedo). Dr. Pepe Esborracha (desastrado), Pôncio Pilatos da Glória (grande guia moral)... As personagens se agrupam em seis segmentos: familiares (Célia, Celiazinha, Cotita, Nair, Pantico, e outros); amigos (Britinho, C. Capua, José Chelinini, Pita, Maneco...); professores (Carvalho, M. Ivone, D. Matilde, Peixotinho, Philippe, Miss Piss, M. Violet); mundo profissional (Banguirre y Menudo, T.T. Bezerra, Bica-Bam-Buda, Pepe Esborracha, Machado Penumbra, Dr. Papa-treta...); mundo social (D. Bambina, Sr. Fíleas, João Jordão, M. Penélope, Rolah...); fazenda (Capitão Benedito, Candoca, Delina...).

Os fragmentos são compostos de variados tipos de discursos como cartas, citações, impressões, diálogos, descrições, relatos, poemas; e o nexo que relaciona uns aos outros diluise facilmente. As associações podem ser feitas por estarem próximos uns aos outros, numa quase seqüência subterrânea, que sugere a trajetória da personagem Miramar. Isso faz da fábula uma organização pouco precisa, mas que permite vislumbrar Miramar na infância e adolescência, com amizades escolares e relações familiares; sua viagem precoce à Europa, as experiências várias dessa aventura; e o posterior Miramar, de volta ao Brasil, em suas relações de trabalho, negócios e amizades, em seu crescente desacerto com a esposa paralelo ao envolvimento com a amante (Rolah), em sua derrocada econômica e sentimental e, finalmente, em seu tempo de escritura das memórias.

Trata-se, ainda, de obra rica na enumeração de pessoas reais, do presente do personagem Miramar (1912 - adulto), além de figuras da História e até de personagens de ficção (73 ao todo), o que denuncia uma convivência entre o real e o ficcional sugerida tanto por Antônio Cândido como por Mário da Silva Brito. O primeiro insinua uma transposição literária das vivências pessoais de Oswald, o segundo afirma que em Miramar "a experiência vivida sofre elaboração ficcional"'viii].

\section{A CRÍTICA}

Havia já em 1923, antes mesmo do lançamento da obra, a expectativa das pessoas mais próximas do autor, como é o caso de Mário de Andrade que se manifesta assim em carta a Manuel Bandeira: "Oswald traz um romance Memórias Sentimentais de João Miramar - segundo me contam interessantíssimo, exageradamente de facção. Morro de curiosidade"[ix]. A ansiedade pelo novo e em especial pelo que representasse as propostas modernistas era normal naquele momento histórico, principalmente porque era necessário dar corpo em prosa às 
proposições da Semana de Arte Moderna, pois até então só se manifestara a poesia.

Os comportamentos e reações que surgiram logo após a publicação da obra foram contraditórios: os acadêmicos não viam além do não sentido da obra e o associavam com a irreverência do autor, considerando piada; os que comungavam das idéias modernistas elogiavam a ousadia e as qualidades do texto inovador, mas o associavam à poesia, como 0 fizera Paulo Prado ao referir-se ao rol de sintagmas que compunham o texto: "Obter em comprimidos minutos de poesia"[x]. O jovem Carlos Drummond de Andrade em O Jornal, edição de 1925 também opinava acerca da personagem há pouco nascida: "João Miramar é um tipo indeciso-bom"[xi]. Ainda em 1925, na revista Estética, Prudente de Morais e Sérgio Buarque de Holanda apresentam uma visão do fragmentário da obra de Oswald e do papel do leitor: "Uma das características notáveis deste romance do Sr. Oswald de Andrade deriva possivelmente de certa feição de antologia que ele lhe imprimiu... A construção faz-se no espírito do leitor. Oswald fornece as peças soltas... É só juntar e pronto."[xii]

Temos nessa visão um leitor dependente do texto, pois the cabe apenas o trabalho de decifrá-lo, pois tudo já está no próprio texto. Essa posição imanentista é criticada por W. Iser, que defende um diálogo entre o potencial do texto e a competência do leitor, insistindo que a concretização do sentido da obra se forma na fusão desses horizontes, uma espécie de entrelugar, que já não é a obra nem mais o leitor.

As posições diferentes ante a obra num mesmo momento histórico revelam um texto pelo menos polêmico, o que combina com o período iconoclasta dos anos vinte e que permite ver a obra como constituinte da história na engrenagem sincrônica do seu tempo. Mas a história da obra se constitui enquanto uma história em si e não dependente das circunstâncias sociais, ao contrário, como constituinte de um contexto.

Até 1933, quando sai a público o romance Serafim Ponte Grande, Oswald havia trilhado o caminho do Manifesto Pau-Brasil (1924) e do Antropofágico (1928), ambos dentro do projeto moderno de ruptura, mas também lançou em 1927 Estrela de Absinto, da Trilogia do Exílio, obra que destoa das que vinha divulgando e que contribui para a formação da imagem de irresponsável, ou pelo menos da falta de rumo em sua produção, com que o estigmatizavam seus críticos na época. A partir de $A$ Escada (1934), há mudança de rumos na produção oswaldiana, que se torna explicitamente ideológica, por adesão ao comunismo. A propósito de suas obras, principalmente as de ruptura como Miramar, "criou-se então a fábula de que eu só fazia piada e irreverência (...) foi propositadamente esquecida a prosa renovada de 22..." [xiii], desabafou assim Oswald de Andrade em entrevista dada a Paulo Mendes Campos em 1950.

Antônio Cândido, na década de quarenta, ao constatar a presença do sarcasmo no texto de Oswald, usa a expressão "sarcasmo por sarcasmo"[xiv], o que provoca uma reação de Oswald num artigo polêmico chamado Antes do Marco Zero, em que é agressivo contra Antônio Cândido e outros críticos a quem chama de "chato boys". Anos depois, em 1970, o crítico reveria 
algumas das suas posições anteriores: "Os meus primeiros artigos, relidos depois de tanto tempo, são cheios de erros e tem aquela agressividade misturada de condescendência que parece tão oportuna nos vinte e cinco anos. Oswald tinha razão de sobra para ficar irritado (...)."[xv]

Vêem-se aí dois momentos históricos e duas leituras, o que revela a diferente competência do leitor, com diferente repertório e cujo horizonte de expectativas foi ampliado. Pode-se dizer que Antônio Cândido, leitor do texto artístico de Oswald, iluminou-o de um outro ângulo e tempo, o que permitiu vê-lo renovado, ou ver o que não havia visto antes. Hans R. Jauss afirma que através desse caminho percorrido

O novo torna-se também categoria 'histórica' quando se conduz a análise diacrônica da literatura até a questão acerca de quais são, efetivamente, os momentos históricos que fazem do novo em uma obra literária o novo; de em que medida esse novo é já perceptível no momento histórico do seu aparecimento; de que distância, caminho ou atalho a compreensão teve que percorrer para alcançar-Ihe o conteúdo e, por fim, a questão de se o momento de sua atualização plena foi tão poderoso em seu efeito que logrou modificar a maneira de ver o velho e, assim, a canonização do passado literário.[xvi]

Nessa referida segunda leitura, Antônio Cândido propõe uma análise conjunta de Miramar e Serafim Ponte Grande, nomeando-as "o par-ímpar" e avaliando-as como obras da rebeldia integral e anárquica, experimentação e descoberta de novos caminhos. Essas obras apresentam um estilo baseado no choque das imagens, das surpresas, das sonoridades, da "descontinuidade cênica" e da "tentativa de simultaneidade". O autor salienta a diretriz satírica das obras, enfatizando a forma como o texto foi composto, de tal modo que a sátira parece recair sobre a maneira empolada como escreviam os acadêmicos - uma vez que Oswald produz um texto oposto àquelas propostas - e não sobre as relações sociais ou a realidade nacional que pouco aparece. Antônio Cândido, portanto, lê o ideológico a partir da sátira ao estético tradicional e não a partir de um engajamento político-social, o que significa resgatar a proposta modernista de uma arte com dois propósitos: a renovação estética e a ideológica.

Com Haroldo de Campos, no artigo Miramar na mira, que serviu de prefácio para a segunda edição da obra em análise (1964), depara-se com uma atitude de quase ressentimento do crítico pela atenção dada a Macunaíma e a pouca dispensada a Miramar. Comparando as duas obras, Haroldo de Campos vai insistir que Mário de Andrade usa procedimentos lingüísticos já empregados por Oswald em Miramar, o que Mário havia já confessado. Assim Campos confere a Miramar o título de "o primeiro cadinho de nossa prosa nova"[xvii]. O crítico compara Oswald a James Joyce e a Thomas Mann no emprego da paródia e na segmentação. Busca, assim, uma origem comum para as obras desses três escritores: o Manifesto Futurista de 
Marinetti. A leitura de Haroldo de Campos, a exemplo das anteriores, posiciona-se claramente a favor do estético e o considera inovador. Mais: fundador. Ora, essa prosa nova- em estilo telegráfico, comespírito moderno, com enfoque cinematográfico, influenciada pelas artes plásticas (Cubismo, Futurismo, Impressionismo), estética do fragmentário - é o novo valor; e um valor novo é uma ideologia na medida que altera os rumos do que era vigente até então, estabelecendo novos horizontes nas expectativas do que seja arte. Essas competências atribuídas a Memórias Sentimentais de João Miramar e seu avizinhamento a grandes autores da literatura mundial, proposto por Haroldo de Campos, conferem à obra status de cânone na história da literatura brasileira.

Haroldo de Campos chamou a atenção para a linguagem da obra, não só por comparar Macunaíma a Miramar e até mostrar que aquela parodia esta, mas em especial para afirmar os propósitos da escrita de Oswald. Miramar contém um falso prefácio escrito por Machado Penumbra (personagem da obra), que com linguagem purista de paraninfo de província comenta e analisa o texto, em estilo telegráfico e com metáfora lancinante, de João Miramar. Penumbra discorre usando discurso velho, repleto de lugares-comuns para comentar técnica nova que nega seu próprio discurso. Isso é irônico. A essa oposição de discursos, ou a esse jogo jocoso e sério feito no pretenso prefácio, Haroldo de Campos justifica como parte das reivindicações de Oswald apresentadas no Manifesto da Poesia Pau-Brasil: "A língua sem arcaísmos, sem erudição. Natural e neológica."

Algumas personagens, conforme Haroldo de Campos, remetem aos empolados parnasianos com os quais Oswald de Andrade conviveu em 1912 (época de João Miramar, de sua história). Entre essas personagens se destacam exatamente Machado Penumbra, Dr. Pôncio Pilatos da Glória, Dr. Mandarim Pedroso e o poeta Sr. Fíleas. Creio que os próprios nomes dessas personagens sugerem, por metonímia ou metáfora, a quem se referem.

Para Alfredo Bosi, Miramar satiriza "o Brasil da aristocracia cafeeira aburguesada nas grandes capitais"[xviii], além de ser "reflexo literário da modernidade mundana a que o escritor pertencia como filho pródigo"[xix]. Essas afirmações põem o crítico entre os que vêem na obra a presença do ideológico, pois constata a preocupação do autor em denunciar, pelo menos ironicamente, o grupo social ao qual pertence, mesmo como filho pródigo. A figura Miramar, contemplativo até no nome, e representativo da aristocracia cafeeira, mesmo que através da mulher, não esconde, nesse grupo social, o comportamento de manutenção do status quo, que Ihe era benéfico na República do Café com Leite. Voltando-se agora para os aspectos artístico da obra, Bosi sugere que Miramar é prosa que poderia seguir a poesia de Paulicéia Desvairada de Mário de Andrade pelo telegrafismo das rupturas sintáticas, pelo simultaneísmo, pela sincronia, pela ordem do subconsciente e pelos neologismos copiosos. Ou seja, Miramar é colagem rápida de signos e processos diretos "sem comparações de apoio"[xx], ou, conforme o Manifesto Pau-Brasil, "palavras em liberdade".

Como, pois, se observa, Alfredo Bosi, embora destaque mais intensamente os aspectos 
artístico da obra, faz também sua referência à questão ideológica no texto em análise; além do que, a proposta de Oswald já é em si uma avaliação ideológica através dos procedimentos de composição artística, pois, enquanto inovador da forma de produzir arte, está propondo novos valores ou caminhos, principalmente os alcançados pela liberdade na escolha dos procedimentos da construção do texto, o que determina uma clara manifestação contrária a tudo que representa a estabilidade e a estagnação. Oportuno dizer que essa visão crítica ocorre no final dos anos 70 e se fundamenta nas leituras de Antônio Cândido e Haroldo de Campos.

Kenneth D. Jackson, ao analisar a prosa vanguardista de Oswald, em texto traduzido para o português em 1978, afirma que

A inovação de Oswald representa uma rejeição, não apenas a estilos artísticos precedentes, mas também ao contexto social, cuja expressão teve ligação estreita com aqueles estilos. Nesse contexto, o estilo vanguardista de Miramar representa mais do que a revolta modernista contra $o$ estilo parnasiano e as grandes personalidades literárias e retóricas que dominavam a literatura brasileira. (...) As críticas de João Miramar nas memórias representam a crítica e a rejeição de Oswald de Andrade ao seu próprio passado.[xxi]

Jackson é bastante direto e muito claro na sua observação: Miramar não é apenas personagem, mas também representa o autor, é seu porta-voz, pois através dele é que se faz a denúncia crítica da realidade de seu tempo, das figuras medíocres que faziam aquele momento histórico. O fragmento "42 SORRENTO" revela opinião do narrador:

Um inglês velho dormia de boca aberta como uma boca enegrecida de túnel sob óculos civilizados.

O Vesúvio esperava ordens eruptivas de Thomas Cook \& Son.

E uma mulher de amarelo informava a um esportivo em camisa que o casamento é um contrato indissolúvel.

O fragmento "88. JABUTICABAS", ironiza a personagem Dr. Pilatos em sua mediocridade de "oh! ah!" e recheio retórico em suas falas de autogabar-se , além de expor satiricamente Dr. Mandarim e suas titulações ocas:

O Dr. Pilatos ficou fulo porque o Dr. Mandarim Pedroso, tesoureiro pé-pé do Banco Nordeste de Engole-Marmanjos e presidente do Recreio Pingue-Pongue, dissera em palestra referidora de um genro seu a frase: - esses incógnitos... 
- Chamar de incógnitos! É um rapaz direito, tem o seu cobrezinho.

E continuou para mim com argumentos de paletó puxado durante a pesquisa de pomar:

- Eu já passei com um almoço por semana e cheguei à posição que cheguei. Sou um autodidata! E já fui citado pelo padre Berlangete da Universidade Católica de Beirute. Escrevi a biografia do patriarca Basílio 8 que foi torrado numa igreja por causa de Orígenes. Irei a Ravena estudar de perto o século 5. As academias orientalistas abrir-me-ão as portas, oh! ah!

O fragmento 72 ainda diz: "Fíleas era um cosmético de sonetos." A denúncia do poder estrangeiro, a crítica às convenções saltam aos olhos, mas não é só: a síntese e a surpresa desses fragmentos remetem ao Manifesto da Poesia Pau-Brasil (embora posterior) que declara a rejeição à mentalidade acadêmica e formal pelo "contrapeso da originalidade nativa".

Jackson insiste: "Pode-se dizer que as Memórias Sentimentais retratam o contexto social brasileiro de um modo caricatural e paródico mais aguçado, porque Oswald estava reagindo contra um estilo e um contexto social do qual participava."[xxii]

Seguramente as personagens da obra simbolizam figuras do mundo real que são postas em julgamento crítico pelo ridículo das situações em que são retratadas. O episódio "81 NOITE INSTITUTAL" satiriza o discurso: "L'univers c'est une immense poésie, la poésie de Dieu, disse o grande Lamennais!' Discursos Sul-Americanos. Machado Penumbra." Discursos brasileiros à moda Machado Penumbra: pomposos, altissonantes e pouco práticos. Aliás, no segmento "89 LITERATURA" há a contraposição do discurso grandiloqüente, imponente e vazio ao discurso simplório e caboclo, direto e objetivo. Não só o falar vazio é motivo irônico, também o são os negócios e a incompetência, como ocorre nos fragmentos 116 e 119: “... mas a Companhia Industrial e Segurista de Imóveis Móveis aceitara o negócio depois do vesgo exame do grande advogado Bica-Bam-Buda". Já no prefácio do satirizado personagem Machado Penumbra está presente o irônico "... é o quadro vivo de nossa máquina social que um novel romancista tenta escalpelar com arrojada segurança dum profissional do subconsciente das camadas humanas". A palavra subconsciente esclarece esse caráter não lógico da organização do discurso na obra e mais, faz compreender a organização subterrânea do enredo e a crítica quase subliminar ao contexto social. Tudo parece sub, até a personagem submerge e se faz caricatural.

Além disso tudo, há, de modo incontestável, a própria interpretação de Oswald de Andrade da sua produção e das suas idéias:

A minha pena foi sempre dirigida contra os fracos... Olavo Bilac e Coelho Neto no pleno fastígio de sua glória. O próprio Graça Aranha quando quis se apossar do modernismo. Ataquei o verbalismo de Rui, a italianitá e a futilitá de Carlos Gomes... Em pintura, abri o caminho de Tarsila... Fui quem escreveu contra o ambiente oficial e definitivo, o primeiro 
Oswald se revela nitidamente um crítico de seu tempo. Não poupou as pessoas que representavam o atravanco à modernidade e impulsionou os que se lhe semelhavam inovadores.

Há um outro viés pelo qual Kenneth Jackson analisa a obra e que também revela a consciência crítica em Miramar. O crítico vê no texto uma leitura horizontal, que forma a experiência cronológica da personagem (infância-mocidade; viagem à Europa; retorno e vida no Brasil), e uma leitura vertical, que constitui a formação da consciência crítica de Miramar. Jackson defende a tese de três Miramar. um primeiro de consciência ingênua em que a narração é "aparentemente sincera, direta e viva"[xxiv] - a personagem na infância até a viagem à Europa. Mas o acúmulo de memórias, à medida que os episódios são relembrados, faz o narrador dar-se conta de "que é incapaz de mudar as direções ou alterar o seu próprio caráter"[xxv] o que traz à tona uma consciência mista entre o ingênuo e o maduro. Veja-se o fragmento 67: "Célia achava que eu devia ter vocação nobilitante... Eu era apenas um fazendeiro matrimonial”. Há nesse momento do relato ainda o tom de leviandade do jovem associado ao de análise de sua vida. $O$ narrador maduro predominará a partir do fragmento "146 VERBO CRACKAR", após a separação de Célia, a perda de Rolah e a derrocada financeira: "Oxalá que eu tivesse sabido que esse verbo era irregular".

"Desse modo, Oswald de Andrade cria, nos três narradores Miramar, níveis de consciência e atitudes críticas diferentes no desenrolar da história da vida de João Miramar."[xxvi] Esses diferentes níveis de consciência não são outra coisa que o Miramar que reage aos acontecimentos, ainda ingênuo; o que observa o rumo e padrão que a sua vida vai assumindo; e, finalmente, o Miramar maduro que escreve suas memórias e que vai negar continuá-las.

Lúcia Helena, no artigo Ficção/ Revolução, de 1985, defende a tese da duplicidade de caminhos da prosa oswaldiana e a distingue pelos procedimentos miméticos. A autora afirma que os textos Os Condenados (tríade inicial) e Marco Zero (posterior a Miramar e Serafim) têm uma configuração mimética de representação, isto é, são obras que reproduzem na linguagem a realidade extraliterária. Ou em suas palavras, trata-se de uma concepção simbólica de mimese que "toma o real e o ficcional como uma totalidade indiferenciada"[xxvii]. De outra sorte, vê Miramar e Serafim como mimese de produção, ou seja, produzem na linguagem uma realidade literária. A isso nomina concepção alegórica da mimese, ou ainda: "mediação dialética entre o real e o imaginário"[xxviii], em que nega a aparência de realidade.

A leitura que Lúcia Helena faz de Miramar também salienta a seqüenciação fragmentada, pois a obra se "recusa como fluxo linear e histórico" [xxix], já que sua linearidade não tem comprometimento com a causalidade cronológica, mas é apreendida precariamente pela 
condução de um fluxo interior e psicológico. Esses flashes descontínuos frustram o prazer do leitor que precisa pensar, não só fruir, pois os saltos das lembranças não ocorrem apenas de um para outro fragmento, mas até no mesmo, dando uma feitura poemática à prosa, diluindo as fronteiras entre ambos. Essa forma de apresentar surpreende o leitor já no primeiro fragmento:

Jardim desencanto

O dever e procissões com pálios

e cônegos

lá fora

E um circo vago e sem mistério

Urbanos apitando nas noites cheias

Mamãe chamava-me e conduzia-me para dentro

do oratório de mãos grudadas.

- O Anjo do Senhor anunciou à Maria que estava para ser a mãe de Deus.

Vacilava o morrão de azeite bojudo em cima do copo. Um manequim esquecido vermelhava.

- Senhor convosco, bendita sois entre as mulheres, as mulheres não têm pernas são como o manequim de mamãe até embaixo. Para que pernas nas mulheres, amém.

Fica difícil negar que essa configuração nova de procedimento, ao romper com modos acadêmicos, que diferiam prosa e poesia cabalmente, não esteja, ao lado da própria apresentação do novo, criticando os valores estéticos e também as concepções de vida representados pelas formas tradicionais de arte. Há que se considerar o sentido histórico da arte que se constrói em si, mas não dissociado da própria História do homem.

Portanto Oswald, ao produzir seu texto com as marcas que tem, está denunciando pela arte que a vida já é outra, diferente da postulada pelos textos academicistas de até então. Tanto uma leitura diacrônica do mundo como uma sincrônica mostram que o momento histórico pósguerra traz consigo a agitação e o descontentamento em relação a uma ordem estabelecida em princípios anteriores à catástrofe bélica de 1914 a 1919. Há pedaços de mundo em desordem, 
há valores dissonantes, há angústias novas também no Brasil.

A concepção alegórica que Lúcia Helena atribui ao texto Miramar, que nega a aparência de realidade, não é porque visse a obra como fruto da alienação do autor, ou fruto de uma concepção ingênua de mundo e de arte. Certamente que a postulação ideológica de Oswald mudou posteriormente por tornar-se explicitamente engajada, o que não lhe confere, nesta obra em análise, de modo algum, o epíteto de anarquista inconseqüente da linguagem, como seus adversários o nomeavam. Seu projeto é ideológico nesse momento, exatamente por anarquizar. Aí reside boa parte de sua proposta crítica. A anarquia é o modo pelo qual se desestrutura o já existente a fim de construir então o novo. Havia em Oswald, como em todo grupo heróico de 22, uma ânsia por uma independência cultural brasileira, por um adonar-se da própria história. Isso se torna possível pelo primeiro passo que foi a revolução estética. Embora chamasse, pela novidade, muita atenção sobre si mesma, a mudança estética não é, em si, o ponto final da proposta modernista, basta que se recordem os discursos da Semana de Arte Moderna para perceber a preocupação de criar uma consciência nacional.

\section{CONCLUSÕES}

Como se deu, enfim, a recepção de Memórias Sentimentais de João Miramar na época de seu lançamento e nas leituras críticas posteriores? Como era proposta modernista, a obra veio quebrando paradigmas e provocou diferentes reações. Os que se lhe opuseram é porque defendiam postulados estéticos diversos do modernismo e, portanto, não só não tinham interesse na obra, como também não procuravam instrumental técnico para valorizá-la. Os que a aplaudiam encontravam nela algo que representasse sua ânsia pelo novo, pelo rompimento com as convenções. Mesmo estes não propuseram leituras significativas para o texto, de tal sorte que as avaliações críticas de vigor só apareceram vinte anos mais tarde com Antônio Cândido. Tratase de uma recepção polêmica pelo estranhamento que provocou: de uma lado, recebendo aplausos pela originalidade; de outro, sendo tachada de obra inconseqüente, fruto de um comportamento anarquista.

Em 1943 acontece a leitura de Antônio Cândido. Ainda que esse primeiro estudo sobre Miramar tenha provocado a reação do autor, trata-se de uma leitura analítica criteriosa e já distanciada do momento conturbado de seu lançamento. A crítica desenvolvida em Estouro e Libertação é reconhecida como verdadeiro estudo do texto de Oswald de Andrade. Na segunda leitura, realizada em 1970, porém, o crítico reconhece "erros" em relação à sua análise de vinte e sete anos antes. A maturidade do estudioso the propiciou instrumentos novos ao enfrentar novamente o texto artístico, o que the permitiu ver mais ou diferente o que julgou ter lido da primeira vez. Destaca-se nessa segunda visada a percepção não mais apenas do fragmentário da obra, mas já sua "descontinuidade cênica"[xxx], sua "tentativa de simultaneidade"[xxxi], o que remete a imagens cinematográficas. Além disso, Antônio Cândido destaca a linguagem satírica da obra que ironiza o discurso grandiloqüente, beletrista e vazio, deixando à mostra uma atitude 
ideológica.

Haroldo de Campos, já antes da segunda leitura de Cândido, salientava as qualidades cinematográficas da prosa oswaldiana, dizendo-a "estrutura fraseológica sincopada e facetada em planos díspares"[xxxii] e também qualificava a estética do fragmentário como "descontinuidade em lugar da ligação, justaposição em lugar da sintaxe habitual"[xxxiii]. Decorre daí a semelhança com o Cubismo. Semelhante a Cândido também é o enfoque satírico proposto através da linguagem. O que Haroldo de Campos revela como diferente é a relação de algumas personagens com pessoas reais, que são mostradas caricaturalmente na obra, e a comparação do texto de Oswald com os de Thomas Mann e James Joyce.

Como a leitura de Alfredo Bosi está contaminada pelas de Antônio Cândido e Haroldo de Campos, pouco se lhes acrescenta, antes as confirma. O que Bosi põe em evidência é a relação Miramarl Paulicéia Desvairada, afirmando que há em Miramar a continuidade de procedimentos poéticos como sincronismos, simultaneísmos, palavras em liberdade, neologismos. Essa leitura também combina com outras do período de lançamento da obra, especialmente a de Paulo Prado.

Apesar de também leitor de Cândido e Campos, Kenneth D. Jackson propõe aspectos novos na recepção das Memórias Sentimentais. Analisa a sepígrafes, que revelam a necessidade de nova luz para ver o que virá: "Acostumar ao vôo as novas asas" "acenda uma candeia no entendimento..." [xxiv] Ainda que veja o que já viram, Jackson salienta a "progressiva tomada de consciência de João, suas viagens e o contexto social que 0 rodeia" $[x x x v]$. O crítico vai buscar a figura humana na obra e não somente os aspectos artísticos de sua composição. Exatamente por isso, vê em Miramar esse "herói em busca de um caráter", que "descobre os novos princípios de mobilidade, liberdade, síntese e simplicidade através do mundo crítico e fragmentado das Memórias Sentimentais"[xxxvi]. Através dessas descobertas da personagem, é que vem a rejeição de João Miramar ao contexto social do qual parece se distanciar sempre mais, e é então que se percebe a colagem do autor na personagem. O crítico norte-americano ainda compara Oswald a Machado de Assis pela utilização de capítulos curtos, e João Miramar a Brás Cubas: "João Miramar está, em certo sentido, relatando memórias póstumas de um eu anterior que não existe mais. No ponto-médio de sua vida, João Miramar não é mais sentimental, mas está procurando no seu passado os únicos significados que the possam dar novas perspectivas."[xxxvii]

Lúcia Helena faz a leitura mais recente de Miramar e atribui à obra um valor artístico singular: produz, na linguagem, uma realidade literária. Esse novo horizonte que ela chama de "concepção alegórica da mimese"[xxxviii] vê a obra como uma coisa em si mesma e não como representação de uma realidade extraliterária. Lúcia Helena não nega as competência já atribuídas ao livro, que ela qualifica, por sua seqüenciação, de "pílulas de memória"[xxxix] ou ainda , a propósito da interrupção das memórias de Miramar: "Um Dom Casmurro oswaldianizado encontra na viuvez (a solidão do que não foi e poderia ter sido) o vislumbre do 
que não se abre para a utopia e se estilhaça na vivência do choque de um conjunto de ruínas lutuosas, cuja figura alegórica básica é a melancolia."[xl]

Aí está, à semelhança de Jackson, uma comparação com Machado de Assis, afinal são ambos textos de memórias.

Lúcia Helena não só emitiu juízo de valor sobre as Memórias Sentimentais, como também teceu comentário a respeito de como Haroldo de Campos fez sua leitura de Miramar. "Munido de um instrumental de base estruturalista, o artigo de Haroldo de Campos está interessado em examinar o romance a partir de uma concepção imanentista do literário, daí sua opção de concentrar-se no exame das relações internas de linguagem e no intercâmbio semiológico da literatura com as artes iconográficas da vanguarda."[xli]

Haroldo de Campos, por seu turno, também comenta os escritos de Antônio Cândido dos anos quarenta: "E Antônio Cândido num estudo de 1943, que - não obstante o tempo decorrido; não obstante a reação que suscitou de parte do próprio Oswald; sem embargo das discussões que ainda poderia comportar (...) segue sendo a mais penetrante análise da ficção oswaldiana de que dispomos (...)."[xlii]

Conforme quem seja o leitor, varia a leitura. Leitores semelhantes, com formação similar e interesse próximo produzem sentidos que se aproximam. Desse modo, não é de estranhar que o scríticos estudados tenham trilhado caminhos parecidos: são uma "comunidade interpretativa"[xliii], muito embora pertencentes a momentos históricos um pouco diferentes. Interessante observar que dos anos 40 aos 80 , os efeitos provocados pela leitura, de um lado, mantiveram-se (o fragmentário da composição, a presença de uma fábula subterrânea, 0 estranhamento da linguagem sincopada); de outro, ampliaram-se (o cinematográfico, o crescimento crítico-humanístico da personagem, a mimese de produção). O leitor, através do modo como recebeu a obra e construiu dialeticamente um sentido, ampliando o seu repertório e criando o novo estético a partir de um produto artístico, constituiu a história da leitura de Memórias Sentimentais.

A s Memórias Sentimentais de João Miramar realizam uma crítica sobre a escritura de memórias, pelo modo como estão organizadas (desorganizadas?) em fragmentos. Ou ainda, ao apresentar assim as memórias, o autor está propondo uma leitura crítica à memória nacional incompleta e estilhaçada e ao discurso pomposo e laudatório que sobre ela está estabelecido. Miramar não deixa de ser um símbolo do brasileiro burguês que busca no velho mundo uma espécie de elo perdido e que se nega a ver em sua terra o seu real espaço. Daí a viagem do herói. No retorno, o seu envolvimento no cotidiano vai revelar um indivíduo ainda não consciente, associando-se a estrangeiros num empreendimento que the traz prejuízos e envolvendo-se amorosamente com uma vedete estrangeira também. É com a perda e a solidão que se dá consciência parcial de si - embora ainda beneficiado pela filha, herdeira da fortuna da 
mãe - e escreve sua história. Somente chega de fato à consciência, quando decide não mais continuar suas memórias, pois então atinge a maturidade irônica ao comentar com o repórter sobre as opiniões que Dr. Mandarim e principalmente Dr. Pilatos emitiram sobre a obra, no fragmento 163:

Disse-me o Dr. Mandarim que os viúvos devem ser circunspectos. Mais, que depois dos 35 anos, mezzo del camin di nostra vita, nossa atividade sentimental não pode ser escandalosa(...) Li as Memórias, antes do embarque, ao Dr. Pilatos. (...) O meu livro lembrou-Ihe Virgílio, apenas um pouco mais nervoso no estilo.

Mais que isso, a referência aventada pelo repórter, no mesmo fragmento, de que será acusado pela crítica por não continuar "tão rico monumento da língua e da vida brasílicas" são exemplos claros não só da consciência crítico-irônica da personagem, como também da transposição evidente dos postulados oswaldianos na voz de Miramar, opinando sobre a academia ou os mais velhos infensos a mudanças. Nessas opiniões está evidente a atitude falsa das afirmações e o descompasso entre a linguagem dos "críticos" e a do texto de Miramar. Nem Pilatos e tampouco Mandarim ou outro "crítico" de fato acompanhavam a extensão do relato de Miramar. Miramar constitui seu relato de memórias de uma linguagem nova, e ao inserir as falas acadêmicas de algumas personagens no discurso da obra e ridicularizá-las, está criticando o que elas representam e revelando o grau de consciência que tem disso.

O levantamento da crítica mais significativa sobre a obra Memórias Sentimentais de João Miramar mostra, de um lado os principais aspectos aventados e estudados sobre o livro, de outro sugere uma leitura em que não se despreze o aspecto ideológico do texto, já que o estético ou artístico tem sido amplamente destacado. Não se trata de tentar provar a presença de um engajamento do texto com alguma corrente sócio-política; o que a crítica deixa ver é que, a par da preocupação estética, ou melhor, através dela, Oswald de Andrade está propondo uma leitura crítica de seu tempo; e mais, propondo uma nova postura artística para uma sociedade fragmentada, onde não mais cabem discursos altissonantes que querem manter nobreza, elegância, valores de tradição; isso tudo nada mais é do que querer agarrar-se a tábuas soltas e perdidas após o naufrágio. A sociedade é mais caótica e o progresso a revoluciona a cada instante. Não cabem mais discursos como o de Dr. Mandarim Pedroso, no fragmento 160, quando discorre sobre o comportamento impoluto dos jovens no clube Recreio Pingue-pongue, por ocasião de uma dança de salão em que faltou luz. Esse discurso que destaca Rui Barbosa e critica os versos futuristas, posto na situação em que foi, sugere exatamente o oposto. $O$ comportamento cordato e cordeiro dos jovens, comparados a São Luíses "os levará mais tarde como maridos aos fulgurantes páramos da ventura conjugal". Parecem objetos, marionetes. Isso tudo ante um Miramar separado da esposa e vindo de uma relação rompida com a amante, é no 
mínimo irônico. Esse mesmo discurso ironiza o "feminismo contemporâneo" contrapondo-o à enaltecida atitude imóvel das garotas na escuridão da dança. O discurso de Mandarim desmorona por si só: o feminismo acaba exaltado pela mobilidade e ação, o que confere à mulher participação - proposta modernista. Oswald escreve pelo avesso e pelo avesso quer ser entendido. Todo discurso retórico em Miramaré a própria ironia do retórico. O clube Recreio Pingue-pongue é um centro de manutenção da situação social, portanto significa o oposto do que Oswald propõe em sua obra inovadora.

Memórias Sentimentais de João Miramar é obra que casa com seu tempo, pois rompe esteticamente com um passado acadêmico por força de um impulso de progresso mundial. Esse progresso, no Brasil, está localizado especialmente em São Paulo - berço da obra - e a fragmentação dessa obra espedaça a organização linear tanto da sociedade que se quer outra, quanto do texto literário que se quer novo. A sociedade que se quer outra é a que existe, mas acrescida da competência de ver-se criticamente. Visão que se pretender irradiar a partir de São Paulo para o país. Aí o papel do modernismo e da obra de arte nova.

Ante uma ideologia dominante repressora, mantenedora de uma situação social e estética atrelada ao passado, disposta a reformas de aparência como as que se faziam no Rio de Janeiro da época, sem interesse de tocar nas feridas de seu tempo, a obra de arte, com uma proposta artística nova, sem o panfletarismo comum nessas ocasiões, é o elemento capaz de sacudir as estruturas na medida em que desvela um indivíduo fragmentado numa sociedade estilhaçada. Oswald faz seu protesto a esse mundo através de um discurso desarticulado. Seu discurso é seu protesto, e um protesto é uma posição ideológica.

Segundo Theodor W. Adorno: "A grandeza das obras de arte consiste unicamente no permitirem expressar o que a ideologia encobre"[xliv]. Aí então a grandeza d e Memórias Sentimentais de João Miramar, que tem o mérito de desmascarar, através da ironia à linguagem do poder - metódica e imponente - um sistema falido de idéias, pois só faz repetir o passado. $E$ ao assim agir, a obra de arte não esconde seu caráter ideológico, aquele que, segundo os olhos de Lúcia Helena, denomina-se elegórico, ou aquele que produz na linguagem uma realidade literária.

Notas:

[i] JAUSS, Hans R, História da literatura como provocação à teoria literária, Editora Ática S.A., São Paulo, 1994, p. 23.

[ii] ARANHA,Graça, $A$ emoção estética na arte moderna, in Gilberto M. Teles "Vanguarda Européia e Modernismo Brasileiro", Editora Vozes, Petrópolis, 1972, p 167.

[iii] PICCHIA, Menotti del, Arte Moderna, in Gilberto M. Teles "Vanguarda Européia e Modernismo Brasileiro" Editora Vozes, Petrópolis, 1972, p. 178. 
[iv] IDEM, IBIDEM, p. 179.

[v] ANDRADE, Oswald de, Manifesto da Poesia Pau-Brasil, in Gilberto M. Teles "Vanguarda Européia e Modernismo Brasileiro", Editora Vozes, Petrópolis, 1972, p.203.

[vi] ARANHA, Graça, estética, Rio de Janeiro, 1924.

[vii] ANDRADE, Oswald de, Manifesto da poesia Pau-brasil, in Gilberto M. Teles "Vanguarda Européia e Modernismo Brasileiro", editora Vozes, Petrópolis, 1972, p.206.

[viii] BRITO, Mário da S., Ângulos e Horizontes, Martins, São Paulo, 1969.

[ix] ANDRADE, Mário de, Cartas a Manuel Bandeira, Simões Editora, Rio de Janeiro, 1958, p.60

[x] PRADO, Paulo, in Alfredo Bosi, História Concisa da Literatura Brasileira, Cultrix, S.P., 1980, p. 406.

[xi] ANDRADE, Carlos Drummond de, Nacionalismo Literário, in O Jornal 23/01/25 p.90.

[xii] MORAIS, Prudente de e HOLANDA, Sérgio Buarque de, Estética, Rio de Janeiro, $\mathrm{n}^{0} 2$, ano 2, p. 218.

[xiii] Em entrevista concedida a Paulo Mendes Campos, publicada pelo Jornal de Notícias de São Paulo, em 08 de Janeiro de 1950.

[xiv] CÂNDIDO, Antônio, Estouro e Libertação, in Brigada Ligeira, Martins, S.P., 1945. P. 11.

[xv] CÂNDIDO, Antônio, Vários Escritos, Duas Cidades, S.P. 1970, p.61.

[xvi] JAUSS, Hans R., A história da literatura como provocação à teoria literária, Ed. Ática, S.P.,1994, p. 45.

[xvii] CAMPOS, Haroldo de, Miramar na mira, in Oswald de Andrade, Obras Completas, Civilização Brasileira, Rio de Janeiro, 1971, p. 14.

[xviii] BOSI, Alfredo, História concisa da literatura brasileira, Cultrix, São Paulo, 1980, p.405.

[xix] IDEM, IBIDEM. p. 406.

[xx] IDEM, IBIDEM. p. 406.

[xxi] JACKSON, Kenneth D., A prosa vanguardista na literatura brasileira: Oswald de Andrade, Editora Perspectiva, São Paulo, 1978, p 30.

[xxii] IDEM, IBIDEM, p. 32.

[xxiii] ANDRADE, Oswald de, Antes do Marco Zero, Ponta de Lança - Obras Completas 5, p. 42

[xxiv] JACKSON, Kenneth D., A prosa vanguardista na literatura brasileira: Oswald de Andrade, Ed. Perspectiva, S.P., 1978, p.40.

[xxv] IDEM, IBIDEM. p. 41 
[Xxvi] IDEM, IBIDEM. p. 42

[xxvii] HELENA, Lúcia. Totens e tabus da modernidade brasileira: símbolo e alegoria na obra de Oswald de Andrade, Tempo Brasileiro, Rio de Janeiro, 1985, p.103.

[xxviii] IDEM, IBIDEM. p.104.

[xxix] IDEM, IBIDEM.p.104

[xxx] CÂNDIDO, Antônio. Vários Escritos, Duas Cidades, São Paulo, 1970.

[Xxxi] IDEM, IBIDEM.

[xxxii] CAMPOS, Haroldo de. Miramar na mira, in Oswald de Andrade, Obras Completas 2, Civilização Brasileira, Rio de Janeiro, 1971, p. 41.

[xxxiii] IDEM, IBIDEM.

[xxxiv] ANDRADE, Oswald de. Memórias Sentimentais de João Miramar, Obras completas 2, Civilização Brasileira, Rio de Janeiro, 1971, epígrafe.

[xxxv] JACKSON, Kenneth D. A prosa vanguardista na literatura brasileira: Oswald de Andrade, Ed. Perspectiva, São Paulo, 1978, p. 42.

[xxxvi] IDEM, IBIDEM. p. 43.

[xxxvii] IDEM, IBIDEM. p. 44.

[xxxviii] HELENA, Lúcia. Totens e tabus da modernidade brasileira, Tempo Brasileiro, Rio de Janeiro, 1985, p. 90.

[xxxix] IDEM, IBIDEM. p. 91.

[X]] IDEM, IBIDEM. p. 95/96.

[xli] IDEM, IBIDEM. p. 87.

[xlii] CAMPOS, Haroldo de. Miramar na mira, idem, p. 15/16.

[xliii] FISH, Stanley. Is There a Text in This Class? Harvard U. Press, Cambridge, 1990. Conceito que estabelece que diferentes grupos, com diferentes expectativas, têm diferente recepção, ou atribuem diferentes sentidos ao texto.

[xliv] ADORNO, Theodor W. in Walter Benjamim et alii, Textos Escolhidos, Abril Cultural, São Paulo, 1975. 
ADORNO, Theodor W. In: BENJAMIM, Walter et alii. Textos escolhidos. São Paulo: Abril Cultural, 1975.

ANDRADE, Oswald de. Memórias Sentimentais de João Miramar. Rio de Janeiro: Editora Civilização Brasileira, 1973.

ANDRADE, Oswald de. In: Ponta de Lança, Obras Completas 5. Antes do Marco Zero. Rio de Janeiro: Editora Civilização Brasileira, 1973.

ARANHA, Graça. In: TELES, Gilberto Mendonça. Vanguarda Européia e Modernismo Brasileiro. A Emoção Estética na Arte Moderna. Conferência em 15.02.1922. Petrópolis: Vozes, 1972.

BOSI, Alfredo. História Concisa da Literatura Brasileira. São Paulo: Cultrix Ltda, 1980.

BRITO, Mário da Silva. História do Modernismo Brasileiro. Rio de Janeiro: Civilização Brasileira, 1964.

CAMPOS, Haroldo de. In: ANDRADE, Oswald de. Obras Completas 2. Miramar na Mira. Rio de Janeiro: Editora Civilização Brasileira, 1971.

CÂNDIDO, Antônio. Vários Escritos. São Paulo: Duas Cidades, 1970.

HELENA, Lúcia. Totens e tabus da modernidade brasileira: símbolo e alegoria na obra de Oswald de Andrade. Rio de Janeiro: Tempo Brasileiro, 1985.

ISER, Wolfgang. $O$ ato de ler: por uma teoria do efeito estético. São Paulo, Martins Fontes, 1995.

JACKSON, Kenneth D. A Prosa Vanguardista na Literatura Brasileira: Oswald de Andrade. São Paulo: Perspectiva S.A., 1978.

JAUSS, Hans R. A história da literatura como provocação à teoria literária. São Paulo: Editora Ática, 1994.

PICCHIA, Menotti del. In: TELES, Gilberto Mendonça. Vanguarda Européia e Modernismo Brasileiro. Arte Moderna. Conferência em 17.02.1922. Petrópolis: Vozes, 1972. 